\title{
FORMULASI KEBIJAKAN PERLINDUNGAN LAHAN PERTANIAN PANGAN \\ BERKELANJUTAN DI KABUPATEN KARAWANG
}

Amalina $^{1}$, Sulistio Diliwanto Binsasi ${ }^{2}$, Hartuti Purnaweni ${ }^{3}$

\begin{abstract}
Abstrak
Penelitian ini dimaksudkan untuk menganalisis Formulasi Kebijakan Perlindungan Lahan Pertanian Pangan Berkelanjutan Di Kabupaten Karawang. Adapun permasalahan di dalam penelitian ini adalah Bagaimanakah Proses Perumusan Kebijakan Perlindungan Lahan Pertanian Berkelanjutan sebagai upaya pengendalian alih fungsi lahan pertanian ke non pertanian. Untuk menjawab permasalahan tersebut maka ditunjang dengan berbagai macam teori dari para ahli yang mempunyai relevansi dengan variabel penelitian. Metode yang digunakan untuk mengumpulkan data yakni observasi dan wawancara dengan menggunakan teknik analisa data deskriptif kualitatif. Setelah peneliti menampilkan data empirik yang di temui di lokasi penelitian.

Hasil penilitian di Kabupaten Karawang dalam perumusan Kebijakan Perlindungan Lahan Pertanian Pangan Berkelanjutan yakni: Proses Perumusan Kebijakan Perlindungan Lahan Pertanian Di Kabupaten Karawang diawali dengan perumusan masalah terkait dengan alih fungsi lahan dan tumbuh suburnya industri-industri di lahan 19 ribu Ha, dan pengurangan lahan pertanian di tahun 2015-2017 yakni $625 \mathrm{Ha}$. oleh sebab itu pemerintah kabupaten karawang menggunakan pendekatan kebutuhan lahan pertanian dan citra satelit untuk mengetahui luasan pertanian yang ada dan menjaga kabupaten karawang tetap eksis sebagai lumbung padi nasional. Dan Pemerintah Kabupaten Karawang memilih alternatif kebijakan terbaik kemudian dimasukan dalam Draf Naskah Akademik terkait Perlindungan Lahan Pertanian Pangan Berkelanjutan yang nantinya akan menjadi draf Peraturan Daerah No 1 Tahun 2018. Alternatif kebijakan perlidungan lahan pertanian pangan berkelanjutan ini juga mengatur tentang insentif bagi petani yaitu adanya subsidi untuk bibit, obat-obatan pertanian, dan alat-alat penunjang pertanian hal ini agar para petani tidak mengalih fungsi lahan pertanian, tetapi 87,5 ribu Ha yang sudah dikunci sebagai zona hijau dan dengan adanya mapping memudahakan bangsa ini dalam mengetahui secara pasti berapa luas lahan pertanian untuk ketahanan pangan.
\end{abstract}

Kata Kunci : Formulasi Kebijakan, Perlindungan Lahan Pertanian

\footnotetext{
${ }^{1}$ Mahasiswa Program Studi Magister Ilmu Administrasi, Departemen Administrasi Publik, FISIP, Universitas Diponegoro Semarang.

${ }^{2}$ Mahasiswa Program Studi Magister Ilmu Administrasi, Departemen Administrasi Publik, FISIP, Universitas Diponegoro Semarang. Email : sulistio.binsasi@yahoo.com

${ }^{3}$ Dosen Program Studi Magister Ilmu Administras Publik \& Program Magister Dan Doktor Ilmu Lingkungan Sekolah Pascasarjana Universitas Diponegoro Semarang
} 


\section{PENDAHULUAN}

Kabupaten Karawang adalah salah satu kabupaten yang berada dalam wilayah Provinsi Jawa Barat. Kabupaten Karawang berada di utara Provinsi Jawa Barat dengan luas wilayah 1.753,27 km atau 3,73 persen dari luas Provinsi Jawa Barat. Karawang yang merupakan Kota Pangkal Perjuangan kemerdakaan ini, juga bertindak sebagai penghasil pertanian bagi Jawa Barat maupun nasional. Ketersediaan lahan pertanian yang melimpah dan keadaan lahan yang subur, menjadikan sebagian besar lahanya digunakan untuk pertanian.

Karawang menyandang sebuah julukan yang memang menggambarkan bagaimana melimpahnya hasil pertanian dan produktivitas pertanian di Kabupaten Karawang sehingga Kabupaten Karawang dijuluki sebagai Lumbung Padi Nasional dimana tercatat penghasil beras terbesar setalah kabupaten indramayu dimana kabupaten Karawang selalu memsurplus beras1,5 Ton pertahun.

Sejarah menjelaskan bagaimana asal muasal Kabupaten Karawang menjadi Lumbung Padi bukan tanpa sebab mengapa akhirnya Kabupaten Karawang menyandang julukan tersebut. Hal ini dikarenakan, Kabupaten Karawang berperan dalam membantu Raja Sultan Agung yang berasal dari Mataram melakukan perlawanan terhadap kebijakan monopoli VOC. Jarak tempuh yang harus dilalui oleh pasukan Mataram mencapai 90 hari, melihat jauhnya jarak dari Mataram menuju ke Batavia pada masa itu. Dengan jarak tempuh yang sangat lama, maka Raja Mataranm dengan matang melakukan pemetaan kawasan dalam penyediaan logistik dan kebutuhan bagi para pasukan Mataaram dengan membangun daerah lumbung-lumbung pangan bagi pasukan tantara Mataram sebelum pertempuran sebenarnya terjadi

- Selain sejarah yang menceritakan bagaimana Karawang sangat berperan bagi pasukan-pasukan Kerajaan Mataram, hasil Produktivitas hasil pertanian di Kabupaten Karawang menjadi sebuah dasar Kabupaten Karawang dapat dijuluki dengan Kota lumbung Padi. Namun keadaan Luasan Lahan pertanian dikabupaten Karawang mulai mengalami penyusutan. Hal ini dapat di lihat dari Tabel 1.1 Lahan Pertanian Berdasarkan Penggunaan Kabupaten Karawang. 
Tabel 1.1

Data Lahan Pertanian berdasarkan Penggunaan KabupatenKarawang

\begin{tabular}{|l|r|r|r|r|r|}
\hline No & Tahun & $\begin{array}{c}\text { Lahan } \\
\text { Pertanian } \\
\text { Sawah } \\
\text { (ha) }\end{array}$ & $\begin{array}{c}\text { Lahan } \\
\text { Pertanian } \\
\text { Bukan Sawah } \\
\text { (ha) }\end{array}$ & $\begin{array}{c}\text { Lahan Bukan } \\
\text { Pertanian } \\
\text { (ha) }\end{array}$ & $\begin{array}{c}\text { Jumlah } \\
\text { (ha) }\end{array}$ \\
\hline 1 & 2013 & 98.079 & - & 116.125 & 175.327 \\
\hline 2 & 2014 & 99.558 & - & 92.370 & 191.928 \\
\hline 3 & 2015 & 96.482 & 39.402 & 39.997 & 175.881 \\
\hline 4 & 2016 & 95.906 & 38.150 & 41.203 & 175.259 \\
\hline 5 & 2017 & 95.536 & 33.424 & 46.299 & 175.259 \\
\hline
\end{tabular}

Sumber: BPS Kabupaten Karawang 2017

Dari data tersebut diatas, dapat dilihat bahwa luas lahan pertanian di Kabupaten Karawang mengalami fluktuatif dimana pada tahun 2013-2014 mengalami kenaikan sebesar 16.601 Ha. Namun pada tahun 2014-2015 mengalami penuruna lahan pertanian sebesar 16.047 Ha, dan di tahun 2015-2017 penurunan lahan pertanian sebesar $652 \mathrm{Ha}$.

Hasil Produktivitas hasil pertanian di Kabupaten Karawang menjadi sebuah dasar Kabupaten Karawang dapat di juluki sebagai Kota Lumbung Padi. Hal ini dapat dilihat dalam tabel 1.2 Produksi Padi Menurut Kabupaten /Kota di Jawa Barat 2010-2015.

Tabel. 1.2

Data Produksi Padi Menurut Kabupaten/Kota di Jawa Barat

(Ton/Tahun), 2010-2015

\begin{tabular}{|l|r|r|r|r|r|r|}
\hline \multicolumn{1}{|c|}{ Wilayah } & \multicolumn{1}{c|}{$\mathbf{2 0 1 0}$} & \multicolumn{1}{c|}{$\mathbf{2 0 1 1}$} & \multicolumn{1}{c|}{$\mathbf{2 0 1 2}$} & \multicolumn{1}{c|}{$\mathbf{2 0 1 3}$} & \multicolumn{1}{c|}{$\mathbf{2 0 1 4}$} & \multicolumn{1}{c|}{$\mathbf{2 0 1 5}$} \\
\hline Indramayu & 1.358 .441 & 1.415 .050 & 1.376 .604 & 1.435 .938 & 1.361 .374 & 1.188 .633 \\
\hline Karawang & 1.133 .978 & 1.135 .863 & 1.076 .066 & 1.147 .212 & 1.122 .582 & 1.188 .633 \\
\hline Subang & 919.789 & 1.059 .905 & 993.661 & 1.022 .571 & 964.845 & 1.028 .009 \\
\hline Garut & 894.197 & 907.011 & 925.239 & 917.503 & 972.890 & 919.971 \\
\hline Cianjur & 862.229 & 790.824 & 868.538 & 882.662 & 830.545 & 851.650 \\
\hline Tasikmalaya & 851.108 & 808.908 & 771.451 & 845.027 & 881.026 & 843.096 \\
\hline Sukabumi & 805.924 & 724.025 & 825.788 & 767.688 & 897.485 & 842.655 \\
\hline Ciamis & 724.842 & 684.837 & 604.882 & 662.779 & 448.641 & 402.641 \\
\hline Bekasi & 590.403 & 574.787 & 492.408 & 537.388 & 439.504 & 447.869 \\
\hline Majalengka & 580.638 & 586.691 & 600.975 & 659.403 & 634.620 & 611.623 \\
\hline Bogor & 538.804 & 497.711 & 494.815 & 559.367 & 517.442 & 492.207 \\
\hline Cirebon & 510.419 & 522.965 & 449.301 & 584.335 & 462.977 & 483.316 \\
\hline Bandung & 459.077 & 464,425 & 479.425 & 503.912 & 475.190 & 433.576 \\
\hline Sumedang & 453.303 & 460.212 & 447.546 & 503.912 & 475.190 & 433.576 \\
\hline Kuningan & 374.925 & 383.962 & 335.867 & 369.242 & 356.550 & 355.015 \\
\hline $\begin{array}{l}\text { Bandung } \\
\text { barat }\end{array}$ & 267.347 & 222.899 & 230.692 & 252.712 & 256.687 & 205.562 \\
\hline Purwakarta & 238.876 & 217.805 & 194.645 & 203.224 & 198.964 & 211.523 \\
\hline Kota banjar & 47.888 & 42.411 & 39.918 & 41.124 & 35.519 & 38.412 \\
\hline
\end{tabular}




\begin{tabular}{|l|r|r|r|r|r|r|}
\hline \multicolumn{1}{|c|}{ Wilayah } & \multicolumn{1}{c|}{$\mathbf{2 0 1 0}$} & \multicolumn{1}{c|}{$\mathbf{2 0 1 1}$} & \multicolumn{1}{c|}{$\mathbf{2 0 1 2}$} & \multicolumn{1}{c|}{$\mathbf{2 0 1 3}$} & \multicolumn{1}{c|}{$\mathbf{2 0 1 4}$} & \multicolumn{1}{c|}{$\mathbf{2 0 1 5}$} \\
\hline $\begin{array}{l}\text { Kota } \\
\text { sukabumi }\end{array}$ & 21.682 & 24.382 & 20.821 & 21.721 & 21.971 & 24.474 \\
\hline Kota Bogor & 8.331 & 9.159 & 6.389 & 3.585 & 2.516 & 3.588 \\
\hline $\begin{array}{l}\text { Kota } \\
\text { Bandung }\end{array}$ & 8.177 & 5.668 & 13.524 & 13.654 & 9.729 & 10.672 \\
\hline Kota Bekasi & 5.708 & 4.583 & 3.750 & 3.926 & 3.522 & 3.050 \\
\hline Kota Depok & 4.828 & 4.985 & 3.962 & 1.880 & 2.031 & 1.475 \\
\hline $\begin{array}{l}\text { Kota } \\
\text { Cirebon }\end{array}$ & 4.300 & 3.842. & 2.027 & 2.384 & 2.271 & 2.245 \\
\hline $\begin{array}{l}\text { Kota } \\
\text { Cimahi }\end{array}$ & 3.806 & 3.276 & 3.154 & 2.846 & 3.353 & 2.240 \\
\hline
\end{tabular}

Sumber: BPS Provinsi Jawa Barat 2017

Dari data tersebut Kabupaten Karawang berada pada urutan ke 2, dimana produktifitas hasil pertanian Kabupaten Karawang mencapai 1,2 Juta Ton/Tahun. Hasil Produktifitas Padi bersifat fluktuatif dimana Pada Tahun 2011-2012 hasil produktifitas padi mengalami penurunan yakni 1.135.863 ton menjadi 1.076.066 ton, dan mengalami kenaikan pada tahun 2013 yakni mencapai 1.147.212 ton dan mengalami penurunan di tahun 2014 yakni 1.122 .582 ton.

Pertanian merupakan kebudayaan yang pertama kali dikembangkan manusia sebagai respons terhadap tantangan kelangsungan hidup yang berangsur menjadi sukar karena semakin menipis nya sumber pangan di alam bebas akibat laju pertambahan manusia. Begitu pula masyarakat Karawang yang masih banyak menggantungkan penghasilan dari sektor pertanian

Letak Kabupaten Karawang sangatlah strategis, dimana Kabupaten Karawang terhubung dengan beberapa kota-kota metropolitan, seperti Bandung, Bekasi dan Ibukota yakni Jakarta. Melihat Kabupaten Karawang yang begitu strategis, Kabupaten Karawang mulai diperhitungkan untuk membangun sebuah kawasan industri, baik yang sudah ada maupun investor yang akan menanamkan modalnya di Kabupaten Karawang. Menjadi sebuah hal yang baik bagi masyarakat dan Pemerintah Kabupaten Karawang, terciptanya lapangan pekerjaan dan memberi pendatan daerah.

Fenomena pertumbuhan industri Kabupaten Karawang yang semakin pesat, sangat kontradiktif dengan predikat Kabupaten Karawang sebagai Lumbung Padi Nasional. Hal ini ditandai dengan berkurangnya jumlah lahan pertanian yang ada di Kabupaten Karawang sebagaimana tercatat di tahun 2015-2017 yaitu 652 Ha. (BPS Kabupaten Karawang Tahun 2017), dan meningkatnya laju alih fungsi lahan pertanian ke 
non pertanian. Alih fungsi lahan pertanian merupakan salah satu ancaman terhadap pencapaian ketahanan dan keamanan pangan. Alih fungsi lahan pertanian selama ini kurang diimbangi oleh pengembangan lahan pertanian melalui pemanfaatan lahan marginal. Di sisi lain, alih fungsi lahan pertanian pangan menyebabkan berkurangnya penguasaan lahan sehingga berdampak pada menurunya pendapatan petani.

Penurunan jumlah lahan di Kabupaten Karawang didorong oleh beberapa faktor, berdasarkan penilitian Anneke Puspasari tentang Faktor-faktor yang mempengaruhi alih fungsi lahan pertanian dan dampaknya trehadap pendapatan petani di Desa Kondangjaya, Kecamatan Karawang Timur, Kabupaten Karawang ditemukan faktor-faktor yang mempengaruhi alih fungsi lahan di Karawang yakni jumlah industri, danproporsi luas lahan sawah terhadap luas wilayah, sedangkan adnya faktor yang mempengaruhi alih fungsi lahan di kalangan petani yakni tingkat usia, luas lahan, lama pendidikan, dan pengalaman bertani .

Menyikapi fenomena tersebut, Pemerintah Kabupaten Karawang perlu mengeluarkan sebuah kebijakan mengenai Perlindungan Lahan Pangan Pertanian Berkelanjutan sebagaimana upaya mencegah alih fungsi lahan pertanian sehingga Karawang tetap menjadi kota lumbung padi nasional dan untuk ketahanan pangan nasional.

Berdasarkan paparan permasalahan diatas, maka penulis ingin mengkaji proses Formulasi Kebijakan Tentang Perlindungan Lahan Pertanian Berkelanjutan sebagai upaya Pemerintah Kabupaten Karawang untuk menjaga eksistensi pertanian di Kabupaten Karawang sebagai Lumbung Padi Nasional. Tujuan Penelitian ini yaitu untuk Menganilisis Formulasi Kebijakan Perlindungan Lahan Pangan Pertanian Berkelanjutan Di Kabupaten Karawang.

Metode yang digunakan dalam penelitian ini yaitu kualitatif deskriptif dengan pendekatan eksploratif. Focus penilitian ini adalah menganalisis Formulasi Kebijakan Pemerintah Kabupaten Karawang dalam Perlindungan Lahan Pertanian Berkelanjutan. Teknik pengumpulan data dalam penilitian ini adalah wawancara, observasi dan studi dokumen sedangkan teknik analisa data Miles dan Huberman.

\section{PEMBAHASAN}

\section{Kebijakan Publik}


Charles O. Jones dalam Winarno, mengatakan bahwa istilah kebijakan (Policy Term) digunakan dalam praktik sehari-hari namun digunakan untuk menggantikan kegiatan atau keputusan yang sangat berbeda. Istilah ini sering dipertukarkan dengan tujuan (goals), program, keputusan (decision), standard, proposal, dan grand design. Thomas R Dye dalam Riant Nugroho bahwa segala sesuatu yang dikerjakan dan tidak dikerjakan oleh Pemerintah, mengapa mereka melakukan hasil yang membuat sebuah kehidupan bersama tampil berbeda

Hugh Heglo dalam Said Sainal Abidin menyebutkan kebijakan sebagai "a course of action intended to accomplish some end" atau sebagai suatu tindakan yang bermaksud untuk mencapai tujuan tertentu. Selanjutnya diuraikan oleh Jones dalam Sainal Abidin dalam Bukunya Kebijakan Publik dalam kaitannya dengan beberapa isi dari kebijakan itu yaitu:

a) Isi yang pertama adalah tujuan; sesuatu yang dikehendaki untuk dicapai.

b) Rencana atau proposal yang merupakan alat atau cara tertentu untuk mencapainya,

c) Program atau cara tertentu yang telah mendapat persetujuan dan pengesahan untuk mencapai tujuan yang dimaksud.

d) Keputusan yakni tindakan tertentu yang diambil untuk menentukan tujuan, membuat dan menyesuaikan rencana serta melaksanakan dan mengevaluasi program.

e) Dampak yakni dampak yang timbul dari suatu program dalam masyarakat Pembangunan Pertanian Berkelanjutan

Menurut Hadi (2005) jika kita mengadopsi definisi pembangunan berkelanjutan dari WCED (Word Commision on Environment and Development) maka pembangunan berkelanjutan adalah pembangunan yang diorientasikan untuk memenuhi kebutuhan generasi sekarang tanpa mengorbankan kemampuan generasi yang akan datang untuk memenuhi kebutuhan mereka. Untuk mencapai tujuan pembangunan berkelanjutan terdaat empat prinsip yang harus dipenuhi, yaitu pemenuhan kebutuhan dasar, memelihara intregitas ekologi, keadilan sosial dan kesempatan menentukan nasib sendiri.

Berdasarkan definisi pembangunan berkelanjutan dari WCED, Organisasi Pangan Dunia mendefinisikan pertanian berkelanjutan sebagai manajemen konservasi basis sumberdaya alam dan orientasi perubahan teknologi dan kelembagaan guna menjamin 
tercapainya da terpuaskanya kebutuhan manusia generasi saat ini maupun mendatang. Pembangunan pertanian berkelanjutan menkonservasi lahan, air, sumber daya genetic tanaman maupun hewan, tidak merusak lingkungan, tepat guna secara teknis, layak secara ekonomis, dan diterima secara social

\section{Perlindungan Lahan Pertanian Pangan Berkelanjutan}

Undang Undang Republik Indonesia Nomor 41 tahun 2009 yang dimaksud dengan Lahan Pertanian Pangan Berkelanjutan adalah bidang lahan pertanian yang ditetapkan untuk dilindungi dan dikembangkan secara konsisten guna menghasilkan pangan pokok bagi kemandirian, ketahanan, dan kedaulatan pangan nasional. Sedangkan perlindungan lahan pertanian pangan berkelanjutan sendiri diartikan sebagai sistem dan proses dalam merencanakan dan menetapkan, mengembangkan, memanfaatkan dan membina, mengendalikan dan mengawasi lahan pertanian pangan dan kawasannya secara berkelanjutan. Menurut Sabiham (2008), pertanian berkelanjutan adalah pengelolaan sumberdaya untuk menghasilkan kebutuhan pokok manusia, yaitu sandang, pangan dan papan, sekaligus mempertahankan dan meningkatkan kualitas lingkungan dan melestarikannya. Definisi tersebut mencakup hal-hal sebagai berikut: pelestarian lingkungan, peningkatan ekonomi masyarakat, dan keadilan. Menurut Rustiadi dan Reti (2008), tersedianya sumberdaya lahan pertanian pangan yang berkelanjutan merupakan syarat untuk ketahanan pangan nasional. Ketersedian lahan pertanian pangan berkaitan erat dengan beberapa hal, yaitu: 1) Potensi sumberdaya lahan pertanian pangan, 2) Produktivitas lahan, 3) Fragmentasi lahan pertanian, 4) Skala luasan penguasaan lahan pertanian, 5) Sistem irigasi, 6) land rent lahan pertanian, 7) Konversi, 8) Pendapatan petani, 9) Kapasitas SDM pertanian serta 10) kebijakan di bidang pertanian.

Melihat permaslahan yang ada di kabupaten karawang terkait dengan maraknya alih fungsi lahan pertanian ke non pertanian, maka pemerintah Kabupaten karawang berperan dalam problem solver dengan mengeluarkan suatu kebijakan yang termuat dalam Peraturan Daerah Kabupaten Karawang nomor 1 tahun 2018 pasal 1 ayat 9, Lahan Pertanian Berkelanjutan yang selanjutnya disingkat P2LB adalah bidang Lahan Pertanian yang ditetapkan untuk dilindungi dan dikembangkan secara konsisten guna menghasilkan pangan pokok bagi kemandirian, ketahanan, dan kedaulatan pangan nasional. 
Proses Formulasi Kebijakan Perlindungan Lahan Pertanian Berkelanjutan Di Kabupaten Karawang:

\section{Agenda Kebijakan}

Suatu masalah untuk masuk kedalam agenda kebijakan harus memenuhi syaratsyarat tertentu seperti apakah masalah tersebut mempunyai dampak yang besar dalam masyarakat dan membutuhkan penanganan yang harus segera dilakukan. Dalam hal ini masalah alih fungsi lahan pertanian pangan di kabupaten Karawang menjadi masalah besar jika tidak ada penanganan segera dari pemerintah karna akan berdampak pada tumbuh suburnya lahan industri yang akan membuat lunturnya citra kabupaten karawang sebagai lumbung padi di jawa barat dan nasional, pentingnya mempertahankan kedaulatan pangan merupakan salah satu tujuan bangsa indonesia karna bangsa yang kuat adalah bangsa yang memiliki kedaulatan dan ketahan pangan yang kuat.

\section{Menentukan Alternatif Kebijakan}

Untuk menentukan dan memilih kriteria alternatif kebijakan sebagai pemecahan sebuah masalah yang disebut pilihan atau alternatif kebijakan untuk menghasilkan satu alternatif terbaik yang kemudian dipilih sebagai sebuah kebijakan yang akan diimplementasikan. Pemerintah kabupaten karawang dalam pemilihan alternatif kebijakan lahan pertanian pangan berkelanjutan diawali dengan mengidentifikasi masalah penyusutan lahan pertanian dan tumbuh suburnya industri-industri di karawang sehingga dinas Pertanian Kabupaten karawang dalam mengatasi permasalahan masalah ini diawali dengan langkah awal yaitu melakukan citra satelit untuk memotret luas lahan pertanian setelah mendapatkan pola ruang dan di cetak dalam peta kerja untuk Dinas pertanian dalam hal ini PKL bekerjasama dengan aparat Desa mensosialisasikan tentang perlindungan lahan pertanian pangan berkelanjutan dan mengkroscek, mensensus lahan pertanian yang masuk dalam zona hijau.

\section{Pemilihan Alernatif Kebijakan}

Setelah dilakukan citra satelit untuk memotret luas lahan pertanian yang ada di Kabupaten Karawang dan dilakukannya sensus oleh PKL dan Pemerintah Desa. Pemerintah Kabupaten Karawang memilih alternatif kebijakan terbaik untuk dipakai dalam menyikapi permasalahan alih fungsi lahan di Kabupaten Karawang. Setelah memilih aternatif kebijakan tersebut, akan dimasukan dalam penyusunan naskah 
akademik terkait Perlindungan Lahan Pertanian Pangan Berkelanjutan yang nantinya akan menjadi draf Peraturan Daerah No 1 Tahun 2018, draf inilah yang akan di godok dan di uji publik agar pemerintah dan warga pemilik lahan sawah untuk dapa bekerjasama dalam mewujudkan tujuan kebijakan ini.

Proses penggodokan memakan waktu kajian 5 tahun karena perda ini berbeda dengan perda-perda lainya yang hanya mencamtumkan luasan wilayah pertanian, Hal ini berbeda dengan penggodogan yang dilakukan Pemerintah Kabupaten Karawang dalam Perda No 1 Tahun 2018, Mulai dari, berapa lahan yang berkurang, adanya lahan pertanian kecamatanya , lahan pertanian di desa, bloknya ada, dan adanya pemilik lahan pertanian, memetakan lahan pertanian, sehingga keluar penguncian 87.5 ribu Ha sebagai lahan perlindungan lahan pertanian di Kabupaten Karawang .

Alternatif kebijakan perlidungan lapahan pertanian pangan berkelanjutan ini juga mengatur tentang insentif bagi petani yaitu adanya subsidi untuk bibit, obat-obatan pertanian, dan alat-alat penunjang pertanian hal ini agar para petani tidak mengalih fungsi lahan pertanian, tetapi 87,5 ribu Ha yang sudah dikunci sebagai zona hijau itu menjadi harga mati dan tidak dapat dialihfungsikan dengan dengan bersinergi dengan dinas lainya sehingga ijin untuk membagun bagunan di zona hijau itu tidak akan bisa dan dengan adanya mapping memudahakan bangsa ini dalam mengetahui secara pasti berapa luas lahan pertanian untuk ketahanan pangan.

\section{Penetapan Kebijakan}

Alternatif kebijakan yang diambil pada dasarnya merupakan kompromi dari berbagai kelompok kepentingan yang terlibat dalam pembentukan kebijakan tersebut dan memepunyai kekuatan hukum yang mengikat. Penetapan kebijakan dapat berbentuk berupa undang-undang, yurisprudensi, keputusan presiden, keputusan-keputusan menteri dan lain sebagainya. Sebagaimana dalam kebijakan Perlindungan Lahan Pertanian Pangan Berkelanjutan di Kabupaten Karawang ini sebelum di jalankan, Draf kebijakan ini diusulkan ke DPRD atau Kepala Daerah Kabupaten Karawang untuk di sahkan sehingga dapat di Implementasikan sesuai peraturan yang berlaku.

\section{PENUTUP}

\section{Simpulan}

Proses Perumusan Kebijakan Perlindungan Lahan Pertanian di Kabupaten Karawang diawali dengan perumusan masalah terkait dengan alih fungsi lahan dan 
tumbuh suburnya industri-industri di lahan 19 ribu, dan pengurangan lahan pertanian di tahun 2015-2017 yakni 625 Ha oleh sebab itu pemerintah kabupaten karawang menggunakan pendekatan kebutuhan lahan pertanian dan citra satelit untuk mengetahui luasan pertanian yang ada dan menjaga kabupaten karawang tetap eksis sebagai lumbung padi nasional. Dari pendekatan inilah kemudian di sensus sampai tingkat Desa untuk mengetahui pasti dan menetapkan zona hijau yakni 87,5 ribu Ha dan pola ruangnya. Dan Pemerintah Kabupaten Karawang memilih alternatif kebijakan terbaik yang yang dipakai untuk mengatasi permasalah alih fungsi lahan tersebut, kemudian dimasukan dalam draf naskah akademik terkait perlindungan lahan pertanian pangan berkelanjutan yang nantinya akan menjadi draf Peraturan Daerah No 1 Tahun 2018, draf inilah yang akan di godok dan di uji publik agar pemerintah dan warga pemilik lahan sawah untuk dapat bekerjasama dalam mewujudkan tujuan kebijakan ini. Alternatif kebijakan perlidungan lapahan pertanian pangan berkelanjutan ini juga mengatur tentang insentif bagi petani yaitu adanya subsidi untuk biit, obaa-obatan pertanian, dan alat-alat penunjang pertanian hal ini agar para petani tidak mengalih fungsi lahan pertanian, tetapi 87,5 ribu Ha yang sudah dikunci sebagai zona hijau dan dengan adanya mapping memudahakan bangsa ini dalam mengetahui secara pasti berapa luas lahan pertanian untuk ketahanan pangan.

\section{DAFTAR PUSTAKA}

Abidin Said Zainal. 2012. Kebijakan Publik Ed. 2. Jakarta: Salemba Humanika.

FAO. 1989. Sutainable Development and Natural Resources Management. Twenty-Fifth Conference, Papaer C 89/2 simp 2, Food and agriculture Organization, Rome.

Hadi, S.P. 2005. Dimensi Lingkungan-Perencanaan Pembangunan. Gadjah Mada University Press: Yogyakarta. 143p.

Hanafie Rita. 2010. Pengantar Ekonomi Pertanian.Yogyakarta; CV Andi Offset.

Nugroho Riant. 2012. Public Policy, Jakarta: PT Elex Media Komputindo (Kompas Gramedia).

Rustiadi, E dan W. Reti .2008. Urgensi Lahan Pertanian pangan Abadi dalam Perspektif Ketahanan Pangan, dalam Arsyad, S dan E. Rustiadi (Ed), Penyelamatan tanah, Air dan Lingkungan. Crestpent Press dan Yayasan Obor Indonesia. p 61-86

Sugiono, 2002, Metode Penelitian Administrasi, Bandung Alfabeta. 
Sabiham, S .2008. Manajemen Sumberdaya Lahan dan Usaha Pertanian Berkelanjutan, dalam Arsyad, S dan E. Rustiadi (Ed), Penyelamatan tanah, Air dan Lingkungan. Crestpent Press dan Yayasan Obor Indonesia. p.3-16

Winarno, Budi.2007. kebijakan Publik; Teori dan proses. Yokyakarta: Med press (Anggota IKAPI).

Undang-undang No.41 Tahun 2009

BPS Kabupaten Karawang Tahun 2017

(https://ejournal.unisba.ac.id/index.php/ethos/article/view/1685).

(http://suaraindonesiakini.blogspot.com/2011/09/karawang-pusat-lumbung-padipasukan.html)

https://repository.ipb.ac.id/jspui/handle/123456789/58101?mode=full 